\title{
Diode and Nd:YAG laser in a case of refractory acne keloidalis nuchae
}

\section{Ravi Kumar Chittoria, Devi Prasad Mohapatra, Friji Meethale Thiruvoth, Dinesh Kumar, Arjun Asokan, Vijayaraghavan Nandhagopal}

Department of Plastic Surgery, JIPMER, Gorimedu, Puducherry 605006, Tamil Nadu, India.

Address for correspondence: Dr. Arjun Asokan, Department of Plastic Surgery, Jawaharlal Institute of Postgraduate Medical Education and Research, Gorimedu, Puducherry 605006, Tamil Nadu, India. E-mail: arjunashokan@gmail.com

\begin{abstract}
Acne keloidalis nuchae (AKN) is a disease of unclear etiology that mainly affects males. Medical treatment of $\mathrm{AKN}$ is difficult, with refractory cases often requiring ablation by laser or surgical resection. We report herein, a 23-year-old male with refractory AKN treated successfully with combined laser ablation, using an 810-nm diode laser and a 1064-nm Nd:YAG laser.
\end{abstract}

Key words:

Acne keloidalis nuchae, diode laser, Nd:YAG laser

\section{INTRODUCTION}

The term acne keloidalis nuchae (AKN) was coined in 1872 by Bazin. ${ }^{[1]}$ AKN is a condition characterized by follicular-based papules and pustules that form hypertrophic or keloid-like scars. The principal sites are the occipital scalp and posterior neck. The condition starts as mildly pruritic papules and pustules on the occipital scalp or nape of the neck. This may subsequently evolve to keloid-like plaques. Later, abscesses and multiple sinus tracts may develop. Patients may also present with cosmetic complaints with scarring alopecia in advanced cases. The condition has a male preponderance with a male:female ratio of approximately 20:1. ${ }^{[2]}$

Treatment of AKN is difficult; numerous modalities have been used with varying degrees of success. There is no single definitive first-line therapy. Early, mild papular disease may respond to potent or superpotent topical steroids (e.g., Clobetasol). Intralesional triamcinolone acetonide injection can be helpful to reduce the size and firmness of papules and nodules. Refractory cases may respond to laser ablation.

\begin{tabular}{|l|l|}
\multicolumn{2}{|c|}{ Access this article online } \\
\hline Quick Response Code: & Website: \\
\hline & www.parjournal.net \\
\hline & \\
\cline { 2 - 2 } & \\
\hline
\end{tabular}

\section{CASE REPORT}

A 23-year-old male presented with multiple papules in the occipital scalp of 3 years duration. His main complaints were cosmetic disfigurement and difficulty in combing the hair. He did not give a history of pruritus. On examination, multiple follicle-based papules were observed over the occipital scalp [Figure 1]. An incisional biopsy confirmed the diagnosis of AKN. Histological examination showed skin with orthokeratosis and with increased pigmentation and periadnexal lymphocytic inflammatory infiltrate [Figure 2].

He was initially treated by dermatologist with eight sittings of intralesional triamcinolone acetonide injections at three weekly intervals, subsequently followed by $\mathrm{CO}_{2}$ laser delivery $-7 \mathrm{~J} / \mathrm{cm}^{2}$ (2 sittings), $5.5 \mathrm{~J} / \mathrm{cm}^{2}$ (1 sitting), and $9 \mathrm{~J} / \mathrm{cm}^{2}$ (1 sitting) - with no significant improvement in the symptoms. He was then referred to the Plastic Surgery Department for further management of the refractory lesions.

Since it was a case of refractory AKN, the patient was taken up for alternate laser treatment. Two modalities of lasers - the Nd:YAG (1064 nm) and the diode laser $(810 \mathrm{~nm})$ - were used as follows: the affected occipital scalp was divided arbitrarily at the midline into two halves and one modality was administered in each half with the intent to find out the modality that had a better response, which would be continued on both halves in subsequent treatments. The right side of the occipital scalp was treated with a diode laser $(1 \mathrm{~Hz} / 1 \mathrm{~s} / 0.5 \mathrm{~W})$ and the left side was treated with a Nd:YAG laser $\left(30 \mathrm{~J} / \mathrm{cm}^{2}\right)$ with a spot 
size of $7 \mathrm{~mm}$. A second treatment sitting with the above settings was repeated after 3 weeks, using the same laser applications on each side of the scalp as in the first treatment. Twelve days after the second sitting, there was complete resolution of the lesions with no residual scarring [Figure 3]. He was kept on observation for any

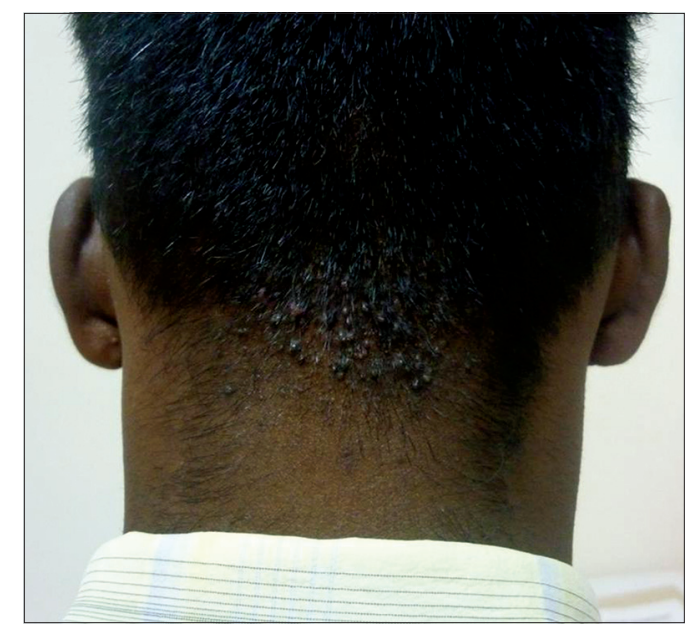

Figure 1: Acne keloidalis nuchae of the occipital scalp after failed $\mathrm{CO}_{2}$ laser treatment and topical steroid and intralesional steroid injection

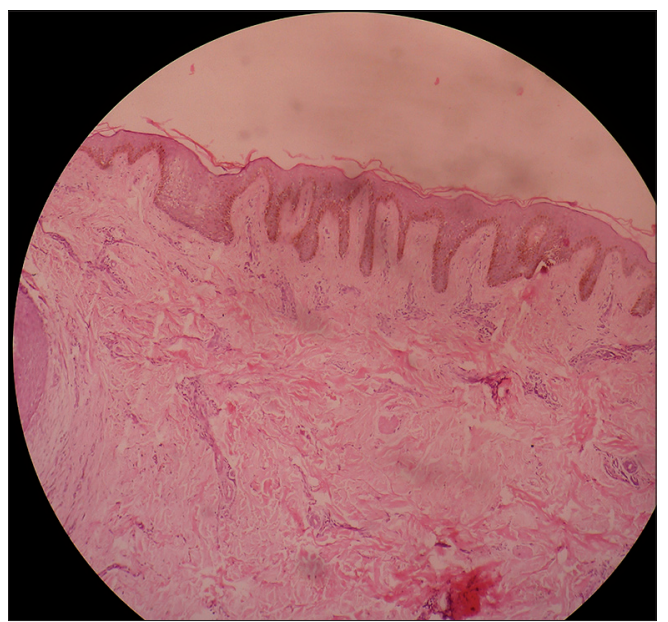

Figure 2: Histological examination showing the skin with orthokeratosis and with increased pigmentation and periadnexal lymphocytic inflammatory infiltration

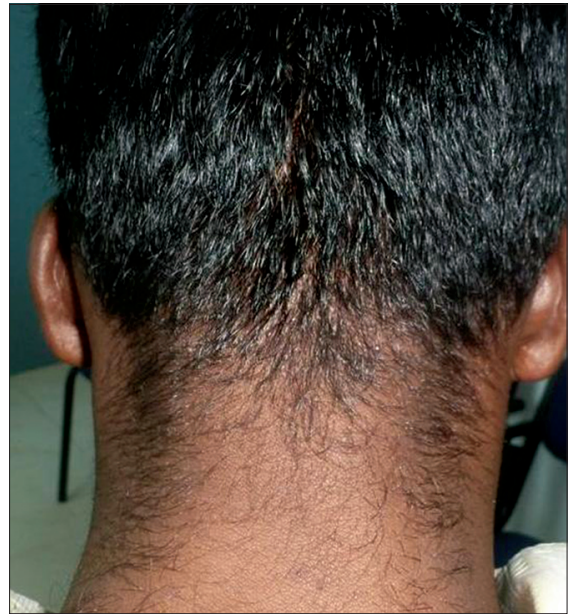

Figure 3: Post-Nd:YAG and -diode laser therapy; the lesion shows good resolution recurrence. The patient was advised to avoid shaving the posterior part of the hairline close to the skin and to avoid wearing clothes that rub or irritate the posterior parts of the scalp and the neck. There was no recurrence of the lesion seen at 15 months follow-up.

\section{DISCUSSION}

AKN has an unclear etiology, with a predominant occurrence in males. The probable causes may be chronic irritation, chronic bacterial infections, or an autoimmune condition. Treatment of AKN is difficult. Early cases may be treated with topical potent steroids or intralesional steroids. Cryotherapy and intralesional 5-fluorouracil have also been tried. Refractory cases may respond to laser ablation (e.g., 10.6- $\mu \mathrm{m}$ carbon dioxide laser, 1064-nm Nd:YAG laser, or 810-nm diode laser). With long-pulsed Nd:YAG lasers at a wavelength of $1064 \mathrm{~nm}$, there is a significant reduction in the papule count, probably due to the higher penetrance of the $\mathrm{Nd}$ :YAG laser into the dermis to disrupt the follicle, sparing the epidermis from heat absorption and thereby minimizing skin damage. ${ }^{[3]}$ A side effect of the Nd:YAG laser is hair fall-out, which grows back, but with thinner hair. The Nd:YAG laser is more suitable for applications in dark-skinned individuals (Fitzpatrick IV, $\mathrm{V}$ and VI types). ${ }^{[3]}$

Diode lasers (using an $810 \mathrm{~nm}$ wavelength) act on the theory of selective thermolysis targeting the melanin in the hair follicles. ${ }^{[4]}$ There is coagulation necrosis of the follicle leading to temporary alopecia. The new hair that regrows, usually after 4-6 months, is much thinner causing less chance of recurrence. Both Nd:YAG and diode lasers act on the principle of selective thermolysis, leading to damage in the hair follicle and thereby causing relief of the disease process. This is in contrast to the earlier concept of using steroids which have mainly concentrated on the anti-inflammatory response, leading to a decrease in disease activity. Laser treatment is a relatively painless procedure with minimal complications. In refractory and advanced cases of $\mathrm{AKN}$, both of these laser modalities may have a role in reducing the number of papules as well as improving the scar cosmetically.

Our patient presented with a refractory AKN, refractory to treatment with topical antibiotics, intralesional steroids, and carbon dioxide laser therapy. We successfully treated the AKN with both diode and $\mathrm{Nd}$ :YAG lasers. In this case, each laser was equally effective in ablation of the lesions, with complete resolution of the symptoms and good cosmetic outcome. However, the risk of hair loss in the treated area should be mentioned to the patient. Furthermore, the chance of the new hair that regrows being much thinner should be emphasized.

Further, large scale randomized control trials are needed for assessing the efficacy and advantage of one modality over the other. 


\section{REFERENCES}

I. Gloster HM Jr. The surgical management of extensive cases of acne keloidalis nuchae. Arch Dermatol 2000;136:1376-9.

2. Kelly AP. Pseudofolliculitis barbae and acne keloidalis nuchae. Dermatol Clin 2003;21:645-53.

3. Attia A, Salah M, Sami N. Novel treatment of acne keloidalis using long pulsed Nd:YAG laser in dark skinned patients. Egypt Dermatol Online J 2009;5:I.
4. Shah GK. Efficacy of diode laser for treating acne keloidalis nuchae. Indian J Dermatol Venereol Leprol 2005;7I:3I-4.

How to cite this article: Chittoria RK, Mohapatra DP, Thiruvoth FM, Kumar D, Asokan A, Nandhagopal V. Diode and Nd:YAG laser in a case of refractory acne keloidalis nuchae. Plast Aesthet Res 2015;2:40-2.

Source of Support: Nil, Conflict of Interest: None declared.

Received: 11-05-2014; Accepted: 15-09-2014 